\title{
A Discussion on How Otolaryngologists Now Correlate Sinusitis with Air Pollution
}

\author{
Ramesh Kumar Sharma* \\ Scientific writer, India \\ *Corresponding author: Ramesh Kumar Sharma, Scientific writer, Bikaner, Rajasthan, India
}

\section{Opinion}

\section{Scientific writer on food and environment issues}

A person inhales daily almost 14 kiloliters of air, breathing on average 18 times a minute, or consumes around 540 milliliters of air per breath; and makes every cell of the body receive oxygen essential for respiration, a biochemical process that releases energy from food within the cells [1]. The nose, the first organ which comes in contact of air in the respiration process, conceptually should be considered the most worthy of attention, when the patients suffering from respiratory diseases are checked by a physician. But the lungs are often x-rayed and sinus is seldom diagnosed. The nasal membrane, inner part is checked if the patient goes to ENT (ear, nose and throat) department. And if he or she approaches to general OPD (out patients department), he or she is generally referred to heart department where he might be x-rayed for the purpose of lung malfunctioning diagnosis. The medical world is perhaps late enough in studying air pollution sinusitis correlation. However, now, the otolaringologists have begun to correlate sinusitis with air pollution. In 1996, Dr. RJ Trevino of Louisiana State University Medical Centre situated at Shreveport (USA) tried to prove that industrial chemical pollutants, present in air, are accumulated in the nasal mucosa and lead to sinus irritation, inflammation, edema, swelling and blocked sinuses resulting in acute and chronic sinusitis; and advised regular intake of dietary antioxidants for sinusitis control [2]. In 2009, N Bhattacharya of otolaringology division of women's Hospital at Boston (USA), conducting a cross-sectional study, found out regression between air quality and prevalence of hay fever and sinusitis; and concluded that prevalence of hay fever and sinusitis are correlated with air quality, that means improved air quality (via removal of pollutants carbon monoxide, nitrous dioxide, sulfur dioxide and particulate matter from the air) leads to decreased prevalence of both the diseases [3]. Some population case studies carried out to know impact of urban air pollution on health reveal the same correlation of air quality with chronic sinusitis [4].
However, the biological and molecular evidences for correlation of air pollution with sinusitis or cause and effect could be provided in 2017, when a group of researchers associated with John Hopkins Medicine reported that experiments in mice continuously exposed to dirty air revealed the direct biological effect [5]. Nineteen mice breathed in filtered air, and 19 breathed polluted air for 6 hours per day, 5 days a week for 16 weeks. And after examinations of used water to flush out noses and sinuses of the both Dr. Murugappan Ramanathan, associated professor at the Johns Hopkins University School of Medicine, and his coworkers concluded that more white blood cells that signal inflammation, including macrophages, neutrophils and eosinophils were found in mice that breathed polluted air compared with those that breathed in filtered air [5]. However filtered air, for example air-conditioning using filtration, of course might prove a good time being remedy; but it is not the permanent solution for sinusitis problem. According to Dr. H. Ganpati, consultant ENT surgeon, Apollo Hospital, Chennai (India), 'People who have a sensitive nose, who are predisposed to allergies, those who are already suffering from an infection, say, common cold, are prone to the ill-effects of air-conditioning [6]. Dr. John Ohman, chief of the division of allergy at Tufts Medical Centre in Boston, opines that the cold air of air-conditioner seems to trigger nervous system reflexes in the nose that cause glands in the nasal membrane to produce mucus and cause sinus congestion; the problem may be particularly in those with allergies [7].

\section{Conclusion}

This brief discussion, on how otolaringologists now correlate sinusitis with air pollution, leads to following conclusions.

a) Filtered air is a time being remedy for respiratory diseases, but air-conditioners equipped with air-filters should not be considered as proper environment for sinusitis control.

b) The natural pollution free air, that does not contain particulate matter as well as gaseous pollutants in appreciable 
amounts, might be proper healthy environment for patients suffering from respiratory and cardiovascular diseases; such a good air quality demands dense bio-diversified forestation.

c) A patient suffering from respiratory and cardiovascular diseases should be investigated for sinusitis too in hospitals. In the opinion of author of this article, WHO (World Health Organization) can make such guideline.

\section{References}

1. (2002) Readers Digest Publications, Sydney. Facts at your fingertips. The human body. Circulation and breathing pp: 136-137.

2. Trevino RJ (1996) Air pollution and its effects on the upper respiratory tract and on allergic rhinosinusitis. Otolaryngol head Neck Surg 114(2): 239-241.
3. Bhattacharya N (2009) Air quality influences the prevalence of hay fever and sinusitis. Laryngoscope 119(3): 429-433.

4. Wolf C (2002) Urban air pollution and health: an ecological study of chronic rhinosinusitis in Cologne, Germany. Health \& Place 8(2): 129139.

5. Ramanathan M, London NR, Thakaran A, Surya N, Sussan TE, et al. (2017) Airborne particulate matter induces non-allergic eosinophillic sinonasal inflammation in mice. American Journal of Respiratory cell and Molecular Biology 57(1).

6. Karthikeyan A (2012) Allergic to air-conditioners? The Hindu.

7. Weintraub K (2017) Can air-conditioners cause sinus congestion? The New York Times.
This work is licensed under Creative Commons Attribution 4.0 License

To Submit Your Article Click Here:

Submit Article

DOI: 10.32474/SJO.2019.02.000131

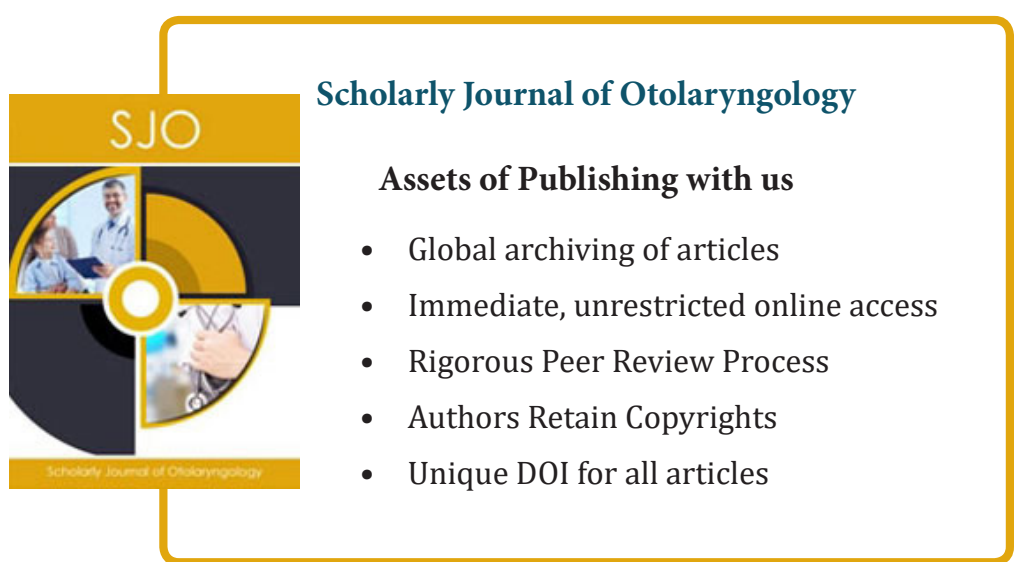

